\title{
Preliminary evaluation of potential prebiotic capacity of selected legumes and seed mucilage on the probiotic strain Lactobacillus rhamnosus GG
}

\author{
Ka Wai Lai ${ }^{a}$, Yu Hsuan How ${ }^{a}$, Hasanah Mohd Ghazalib, Liew Phing Pui ${ }^{*}$ \\ aDepartment of Food Science with Nutrition, Faculty of Applied Sciences, UCSI University, No. 1, Jalan Menara Gading, UCSI Heights, \\ 56000 Cheras, Kuala Lumpur, Malaysia \\ ${ }^{b}$ Department of Food Science, Faculty of Food Science and Technology, Universiti Putra Malaysia, 434000 UPM Serdang, Selangor, \\ Malaysia
}

Received 2nd November 2020 / Accepted 26th January 2021

\begin{abstract}
The characterization of the prebiotic potential of legumes and mucilage are essential and crucial for the development of symbiotic food products. The aim of the present study was to compare and to determine the prebiotic capacity of selected legumes, namely adzuki bean, mung bean, black cowpea, and mucilages from chia seed and flaxseed on the growth of Lactobacillus rhamnosus GG. Resistance towards acid, pancreatin hydrolysis, and the prebiotic scores of the tested substances was determined based on growth promotion after $24 \mathrm{~h}$ of incubation. Results revealed that flaxseed mucilage was more resistant against hydrolysis by acid (1.47\%) and pancreatin (2.64\%) compared to the other samples $(5.64-18.06 \%$ for acid and $10.34-15.57 \%$ for pancreatin). The relative prebiotic scores for flaxseed mucilage and black cowpea were $98 \%$ and $94 \%$, respectively, which were higher than commercial prebiotics including inulin, fructooligosaccharides, and isomaltooligosaccharides. The optimum concentrations of flaxseed mucilage and black cowpea during $36 \mathrm{~h}$ of fermentation were $0.8 \%$ and $0.4 \%(\mathrm{w} / \mathrm{v})$, respectively. The findings indicated that flaxseed mucilage was partially digested during gastrointestinal transit and it promotes the growth of the L. rhamnosus GG. The potential prebiotic capacity of flaxseed mucilage and its symbiotic relationship with $L$. rhamnosus GG suggests that they can be incorporated together for the development of functional foods.
\end{abstract}

Keywords: Functional foods, Lactobacillus rhamnosus GG, legume flours, prebiotics, prebiotic capacity, seed mucilage

\section{INTRODUCTION}

The symbiotic relationship between the indigenous microbial community in the digestive tract is crucial in maintaining intestinal homeostasis, thereby keeping the body healthy (Gagnière et al., 2016). However, the imbalance in the composition of gut microbiota (or dysbiosis) is associated with both intestinal (irritable bowel syndrome and celiac disease) and extra-intestinal disorders such as metabolic syndrome and obesity (Carding et al., 2015; Heeney et al., 2018; Ramakrishna, 2013). Therefore, administration of prebiotics and/or probiotics has been suggested

*Author for correspondence: Liew Phing Pui, Department of Food Science with Nutrition, Faculty of Applied Sciences, UCSI University, No. 1, Jalan Menara Gading, UCSI Heights, 56000 Cheras, Kuala Lumpur, Malaysia. Email - puilp@.ucsiuniversity.edu.my 
as one of the approaches to modulate the equilibrium of the intestinal microbiota (Tungland, 2018).

Probiotics are living non-pathogenic strains of strictly selected microbes that confer therapeutic benefits to the host when administered in an adequate amount (Chew et al., 2019; Hill et al., 2014). Prebiotics has been defined as 'a substrate that is selectively utilized by a host conferring health benefits' (Gibson et al., 2017). The consumption of prebiotics has been associated with the prevention of constipation, infectious and antibiotic-associated diarrhoea, inflammatory bowel disease, metabolic syndrome, obesity, and enhancing the uptake of certain mineral (Slavin, 2013; Taiseer et al., 2014; Zhang et al., 2018). Due to increasing health awareness among consumers, the demand for functional foods, namely probiotics and prebiotics has expanded greatly (Lai et al., 2020a; Singla \& Chakkaravarthi, 2017; Zaman \& Sarbini, 2016). Common prebiotics such as mannitol, isomaltooligosaccharides, and oligofructose had been reported to protect the viability of probiotics (Chan \& Pui, 2020; $\mathrm{Ng}$ et al., 2019; Siang et al., 2019; Yee et al., 2019; Yong et al., 2020).

The increase in consumers' awareness on the importance of the human microbiota has led to an upsurge in the demand for probiotics and prebiotics due to their beneficial effects on overall health by maintaining gut homeostasis. Recently, more studies were focusing on the potential prebiotic effects from legumes and seed mucilage (Bustamante et al., 2015; Monk et al., 2017). Legumes are rich in slowly digestible oligosaccharides and resistant starch that may exert potential prebiotics effects on the different probiotic strains (Winham et al., 2017; Wu et al., 2015). Furthermore, various legumes such as mung bean and adzuki bean have also been reported to maintain the viability of $L$. rbamnosus GR-1 in yoghurt throughout cold temperature storage (Soltani et al., 2018). In addition, mice fed with cooked black bean altered the gut microbiota community by stimulating the growth of the beneficial bacteria and enhanced the production of short-chain fatty acids (Monk et al., 2017).

On the other hand, mucilage is the gel-like soluble fibre that envelops a seed and is secreted by mucilage secreting cells upon hydration (Kreitschitz \& Gorb, 2018). Previous studies had also reported that mucilage from basil seed (Wongputtisin \& Khanongnuch, 2015), psyllium husk seed (Esmaeilzadeh et al., 2016), and bush mint seed (Mueller et al., 2017) showed high prebiotic potential on stimulating the growth of probiotics. Flaxseed is composed of about 11$15 \%$ of mucilage and it consists of a mixture of rhamnogalacturonan I and arabinoxylan, where the latter has been found to have prebiotic activity (Lai et al., 2020b; Lai et al., 2020c; Naran et al., 2008; Pastell et al., 2009; Singer et al., 2011). In addition, chia seed contains about $5-6 \%$ of mucilage that is made up of $\beta$-D-xylopyranosyl, $a$ D-glucopyranosyl, and 4-O-methyl-a-Dglucopyranosyl-uronic acid unit in the ratio 2:1:1 (Muñoz et al., 2012). Hence, both legumes and mucilage-bearing seed may be regarded as potential sources of prebiotics.

Since there is little published data on the comparison of the potential prebiotic effects of legumes and seed mucilage on a specific bacteria strain, it is worthwhile to study the prebiotic effects of selected legumes and seed mucilage on the growth of probiotics such as Lactobacillus rhamnosus GG. Thus, this study aims to determine and compare the prebiotic effects of adzuki bean (Vigna angularis), mung bean (V. radiata) and black cowpea ( $V$. unguiculata) and seed mucilage from chia seed (Salvia hispanica) and flaxseed (Linum usitatissimum) on the growth of L. rhamnosus GG. The optimum concentration of the selected legumes and seed mucilage during fermentation was also determined.

\section{MATERIALS AND METHODS}

\section{Materials}

LactoGG capsules (LactoGG, USA) containing L. rhamnosus GG ATCC 53103 were purchased from a local pharmacy in Malaysia. Adzuki bean (Vigna angularis (Willd.) Ohwi \& H. Ohashi), mung bean (Vigna radiata L.), black cowpea (Vigna unguiculata (L.) Walp), chia seed (Salvia bispanica L.) and flaxseed (Linum usitatissimum L.) were purchased from the local supermarket in Cheras, Kuala Lumpur, Malaysia. The scientific names and type of legumes used in this study were identified and verified by the Institute of Bioscience, Universiti Putra Malaysia. 


\section{Preparation of legume powder and seed mucilage}

The legume powder of adzuki bean, mung bean, and black cowpea was obtained by milling using a miller (Panasonic MX-800S, Japan) and sieved through a $0.5 \mathrm{~mm}$ sieve to obtain the fine powder (Wani et al., 2010). Flaxseed mucilage was produced by using hot water extraction $\left(90^{\circ} \mathrm{C}, \mathrm{pH}\right.$ 5.0, 30 min under $100 \mathrm{rpm}$ agitation) at a ratio of 1:10 for seed: water (Esparza et al., 2011), while the chia seed mucilage was hot water-extracted at $80^{\circ} \mathrm{C}, \mathrm{pH} 6.0,2 \mathrm{~h}$ under $100 \mathrm{rpm}$ agitation at a ratio of 1:40 for seed: water (Muñoz et al., 2012). After agitation, the mucilage was separated from the seed by filtration through a piece of cheesecloth. The filtrate containing extracted mucilage was transferred into petri dishes and dried in a conventional oven at $60^{\circ} \mathrm{C}$ for $16 \mathrm{~h}$. The dried mucilage was peeled from the petri dishes and ground into a fine powder using mortar and pestle.

\section{Determination of resistance towards acid and pancreatic enzymatic hydrolysis}

The resistance of the samples towards simulated acid and pancreatic enzymatic hydrolysis was determined according to Azmi et al. (2012) and Majeed et al. (2018b), respectively, with some modifications. Artificial human gastric acid juice $(\mathrm{g} / \mathrm{mL})$ was prepared to contain $6.2 \mathrm{~g} \mathrm{NaCl}, 2.2 \mathrm{~g}$ $\mathrm{KCl}, 0.22 \mathrm{~g} \mathrm{CaCl}_{2}, 1.2 \mathrm{~g} \mathrm{NaHCO}_{3}$ and $0.3 \%(\mathrm{w} / \mathrm{v})$ pepsin (Chemsoln, India) in $1 \mathrm{~L}$ of distilled water with $\mathrm{pH}$ adjusted to 1 and 5 using $5 \mathrm{M} \mathrm{HCl}$. To prepare artificial pancreatin solution, pancreatin (Chemsoln, India) at $1 \mathrm{mg} / \mathrm{mL}$ was dissolved in $50 \mathrm{mM}$ phosphate buffer, $\mathrm{pH}$ 7.4. The sample solution at a concentration of $1 \%(\mathrm{w} / \mathrm{v})$ was prepared by dissolving $0.1 \mathrm{~g}$ of the sample powder into $10 \mathrm{~mL}$ of distilled water and placed in a sonicator bath (WUC-A06H, Daihan Scientific Co. Ltd., Korea) for $3 \mathrm{~min}$. To perform the test, 5 $\mathrm{mL}$ of artificial gastric acid juice or the enzymatic pancreatin solution was added to $5 \mathrm{~mL}$ of the sample solution and incubated in a shaking water bath (Cole-Parmer, USA) at $37^{\circ} \mathrm{C}$ for $240 \mathrm{~min}$ at $100 \mathrm{rpm}$. Aliquots $(1 \mathrm{~mL})$ were withdrawn periodically at every hour to determine the reducing sugar content using the dinitrosalicyclic acid (DNS) method and total sugar content by phenol-sulphuric acid assay according to Miller (1959) and Dubois et al. (1956), respectively. Fructooligosaccharides (FOS) (Sensus, Netherlands) was used as the reference. The percent of hydrolysis was calculated using the formula represented by Equation 1:

$$
\text { Percent of hydrolysis }(\%)=\frac{\text { Reducing sugar released }}{\text { Total sugar content }- \text { initial reducing sugar content }} \quad \text { X } 100
$$

where the reducing sugar is the difference between its final and initial content, while the initial reducing sugar was the reducing sugar at $0 \mathrm{~h}$.

\section{Determination of prebiotic activity score}

The prebiotic effect of samples was determined according to Thuaytong and Anprung (2011) with slight modifications. The reaction mixture $(0.5 \%$ $\mathrm{w} / \mathrm{v})$ for the selected legumes and seed mucilage was prepared by dissolving the respective powder into $30 \mathrm{~mL}$ of distilled water in a sonicator bath for $3 \mathrm{~min}$. After that, $0.3 \mathrm{~mL}$ of an overnight $L$. rhamnosus GG culture $(1.0 \% \mathrm{v} / \mathrm{v})$ was added to each reaction mixture. Glucose $(0.5 \% \mathrm{w} / \mathrm{v})$ was used as the reference for this test, while FOS, inulin (Sensus, Netherlands), galactooligosaccharides (GOS) (Chemsoln, India) and isomaltooligosaccharides (IMO) (CK Ingredient, Malaysia) served as the positive controls. De Man, Rogosa \& Sharpe (MRS) broth devoid of glucose was used as the negative control. Viable cell counts before $(0 \mathrm{~h})$ and after incubation for $24 \mathrm{~h}$ at $37^{\circ} \mathrm{C}$ were determined by the drop plate method (Yeung et al., 2016). An aliquot $(1 \mathrm{~mL})$ of the broth cultures was withdrawn and serially diluted with $9 \mathrm{~mL}$ of phosphate buffer saline (PBS, Lonza, USA). The enumeration was determined after $48 \mathrm{~h}$ of incubations at $37^{\circ} \mathrm{C}$. The $\log$ viable cell count and the prebiotic scores were calculated using Equations 2 and 3 (Khorasani \& Shojaosadati, 2016): 
Log viable cell count $(\mathrm{CFU} / \mathrm{ml})=\quad \log \frac{\text { Mean number of cells in triplicates }}{\text { Volume plated } \mathrm{x} \text { dilution factor }}$

Prebiotic scores $=\frac{[\log (\mathrm{CFU} / \mathrm{ml}) \text { on prebiotic at } 24 \mathrm{~h}-\log (\mathrm{CFU} / \mathrm{ml}) \text { on prebiotic at } 0 \mathrm{~h}]}{[\log (\mathrm{CFU} / \mathrm{ml}) \text { on glucose at } 24 \mathrm{~h}-\log (\mathrm{CFU} / \mathrm{ml}) \text { on glucose at } 0 \mathrm{~h}]} \times 100$

\section{Determination of selected ingredients' concentration with optimum prebiotic capacity}

The selected ingredients with the highest prebiotic score were then evaluated at different concentrations $(0.2-1.0 \% \mathrm{w} / \mathrm{v})$ to determine the optimum concentration in growth stimulatory effect after $36 \mathrm{~h}$ of incubation in MRS broth (Azmi et al., 2012). The viability of L. rhamnosus GG was determined by drop plate method after $48 \mathrm{~h}$ of incubation at $37^{\circ} \mathrm{C}$ with the initial $(0 \mathrm{~h})$ cell population fixed at $10^{4} \mathrm{CFU} / \mathrm{mL}$ in $100 \mathrm{~mL}$ growth media with the selected ingredient (Yeung et al., 2016). Changes in the $\mathrm{pH}$ of the broth cultures were measured every $3 \mathrm{~h}$ using a calibrated $\mathrm{pH}$ meter. Titratable acidity (TA) was determined every $3 \mathrm{~h}$ based on AOAC (1998) method by titrating $10 \mathrm{~mL}$ of sample broth diluted with $40 \mathrm{~mL}$ of distilled water with $0.1 \mathrm{~N} \mathrm{NaOH}$ to a phenolphthalein endpoint. The volume required was recorded and the TA was expressed as percent lactic acid.

\section{Statistical analysis}

All tests were carried in triplicates and the results were reported as mean \pm standard deviation. One-way variance analysis (ANOVA) and Tukey's post hoc test was performed and when $\mathrm{p}$ $\leq 0.05$ is considered significantly different using IBM SPSS Statistics version 24.

\section{RESULTS AND DISCUSSION}

Figure 1a, 1b and 1c present the percent of hydrolysis of the selected legumes and seed mucilage in artificial acid solution $(\mathrm{pH} 1$ and $\mathrm{pH}$ 5) and pancreatic enzyme at $\mathrm{pH} 7.0$, respectively. The percent of hydrolysis for the all selected legumes and seed mucilage was significantly $(\mathrm{p} \leq$ $0.05)$ higher at lower $\mathrm{pH}(\mathrm{pH} 1)$ as compared to $\mathrm{pH}$, for the artificial acid solutions. This could be due to the acid hydrolysis on the polysaccharides in the samples into reducing sugars such as glucose (Miloski et al., 2008). It was also observed that the percent of hydrolysis increases as the incubation time increases, indicated by the production of more reducing sugars. A similar trend was also reported when bamboo shoot crude polysaccharides and arrowroot starch was treated with simulated gastric juice, more reducing sugars were produced as the incubation time increases (Azmi et al., 2012; Faridah et al., 2017).

In the present study, fructooligosaccharides (FOS) exhibited high tolerance toward simulated gastrointestinal conditions with more than $97 \%$ remaining intact after $4 \mathrm{~h}$ of incubations at both conditions (Figure 1). The percent of hydrolysis of selected legumes ranged from $10.8 \%$ for adzuki bean to $18.1 \%$ for black cowpea at $\mathrm{pH} 1$ (Figure 1a) while $5.7 \%$ for adzuki bean to $13.1 \%$ for black cowpea at $\mathrm{pH} 5$ (Figure 1b). This may be attributed to the breakdown of sucrose in the legumes by $\mathrm{HCl}$ from the artificial acid solution while soluble fibre of seed mucilage slowed down gastric emptying (Bernacchia et al., 2014; Miloski et al., 2008). The release of reducing sugars from the legumes could be enhanced by high sucrose content (in the legume) and at low $\mathrm{pH}$ of gastric juice (Chavan et al., 2015; Miloski et al., 2008). Hence, the high hydrolysis demonstrated by black cowpea in this study could be due to its higher amount of sucrose as compared to both adzuki bean and mung bean (Fan et al., 2015). Nevertheless, the 3 legumes (black cowpea, adzuki bean, mung bean) in this study demonstrated lower hydrolysis as compared to red kidney bean at low $\mathrm{pH}$ after 4 hours $(\sim 25 \%)$ (Saad et al., 2020).

In contrast to legumes, the degree of hydrolysis at the end of incubation at $\mathrm{pH} 1$ ranged from $1.5 \%$ for flaxseed mucilage to $5.6 \%$ for chia seed mucilage (Figure 1a) and both seed mucilages exhibited more than $98 \%$ of resistance towards gastric acid at pH 5 (Figure 1b). The degree of hydrolysis of the selected legumes was higher than 
both seed mucilage and FOS, indicating that the seed mucilage has a higher resistance towards acid hydrolysis as compared to the selected legume flour. The lower degree of hydrolysis displayed by flaxseed mucilage could be due to the higher hetero-polysaccharide $(70 \%)$ such as galactomannan as compared to chia seed mucilage (65\%) (Cruz-Rubio et al., 2018). Galactomannan is resistance towards gastric acid and digestive enzymes, hence improving the degree of hydrolysis (Majeed et al., 2018a).

Mucilage is the soluble dietary fibre extracted from the seed that could retain in gastrointestinal for a longer period (Singer et al., 2011; Suri et al., 2016). Similar results were reported by Emaga et al. (2012) where flaxseed mucilage subjected to low $\mathrm{pH}$ of $0.2 \mathrm{M}$ sulphuric acid for 4 hours showed approximately $1 \%$ of hydrolysis. Furthermore, higher hydrolysis (approximately $9 \%$ ) were also found when the acid concentration was increased to $1 \mathrm{M}$ and $2 \mathrm{M}$. Moreover, Bustamante et al. (2017) also demonstrated chia seed and flaxseed mucilage protective effect towards probiotics throughout gastrointestinal digestion. This support that flaxseed and chia seed mucilage are not easily digested by the gastric acid.

Figure 1c shows that the degree of hydrolysis using pancreatic enzymes ranged from 2.64\% (flaxseed mucilage) to $10.34 \%$ (chia seed mucilage) and from $12.65-15.57 \%$ (for the legumes) after $4 \mathrm{~h}$ of incubation. The present findings revealed that only flaxseed mucilage showed the highest tolerance towards enteric digestion, which was similar to the control (FOS). The highest percent of hydrolysis was obtained by black cowpea $(15.57 \%)$ possibly due to higher carbohydrate composition in black cowpea (61$69 \%$ ) than the adzuki bean and mung bean (5459\%) (Adamu et al., 2016; Brishti et al., 2017; Hamid et al., 2016). Hence, more carbohydrates could be broken down from acid and enzyme hydrolysis (Amezcua-Allieri et al., 2017). Thakur et al. (2018) reported that the pancreatic hydrolysis rate of bamboo shoots and potato peel (about $7 \%$ ) which were similar to those of legume flour obtained in the present study.

Approximately $82 \%$ of the legumes examined remain undigested in the artificial acid solutions (Figure 1a and 1b) and the pancreatin enzymatic solution (Figure 1c) due to the present of nondigestible oligosaccharides. The reported total non-digestible oligosaccharides for adzuki bean, mung bean and black cowpea were $49.8 \mathrm{~g} / \mathrm{kg}, 45.5$ $\mathrm{g} / \mathrm{kg}$ and $69.8 \mathrm{~g} / \mathrm{kg}$, respectively (Fan et al., 2015). In addition, the results may be due to the presence of $\alpha$-amylase inhibitors in adzuki bean, mung bean and black cowpea (Piergiovanni \& Gatta, 1994; Ueda et al., 2004; Wisessing et al., 2010). These findings suggested that the selected legumes and seed mucilage were partially digested during the gastric and intestinal region and the remaining undigested substrate could possibly serve as the prebiotic source for the commensal bacteria in the gut including Lactobacillus rhamnosus GG.

The prebiotic scores are used to estimate the health effects of prebiotic in humans through its ability to stimulate growth of probiotics (Figueroa-González et al., 2019). Figure 2 depicts the comparison of the prebiotic scores on the legumes and seed mucilage examined, commercial prebiotics and glucose. Glucose has the highest prebiotic score $(100 \%)$ due to its highest growth promotion in L. rhamnosus GG after $24 \mathrm{~h}$ of incubation. Glucose is the most common carbon source that supports a good growth rate of many lactobacilli (Sánchez et al., 2010; Succi et al., 2017). Results revealed that the prebiotic scores of adzuki bean, mung bean and commercial prebiotics including FOS, isomaltooligosaccharides (IMO) and inulin were in the range of $79-82 \%$ which are not significantly different $(p>0.05)$ with each other. However, MRS broth without prebiotic has the lowest prebiotic score $(43.51 \%)$ due to lack of carbohydrates sources for growth. This highlights the importance of carbohydrates that is required for the growth of L. rhamnosus GG (Azmi et al., 2012).

The prebiotic scores of flaxseed mucilage and black cowpea were not significant $(p>0.05)$ different from glucose and were higher compared to commercial prebiotics particularly FOS, inulin, and IMO. The present findings are consistent with the study conducted by Watson et al. (2013) who reported that L. rhamnosus GG grew moderately when either inulin or FOS was the sole carbon source. The high prebiotic score of flaxseed mucilage (98.08\%) was possibly attributed to the monosaccharide residues (i.e. fucose, arabinose, fructose and galactose) in the flaxseed mucilage which were utilized by $L$. rhamnosus GG for growth (Kankainen et al., 2009; 
Petrova et al., 2018). Flaxseed mucilage has been reported to increase the generation of short-chain fatty acids like acetate, propionate and butyrate in batch cultures by pig intestinal digesta which are necessary for growth (Lin et al., 2011). Previous studies also demonstrated that the novel prebiotic source from fenugreek seed fibre, cranberry seed fibre, and fungi polysaccharides could exhibit a growth stimulatory effect on the tested strains similar to the commercial prebiotic (Majeed et al., 2018a; Majeed et al., 2018b; Nowak et al., 2016).
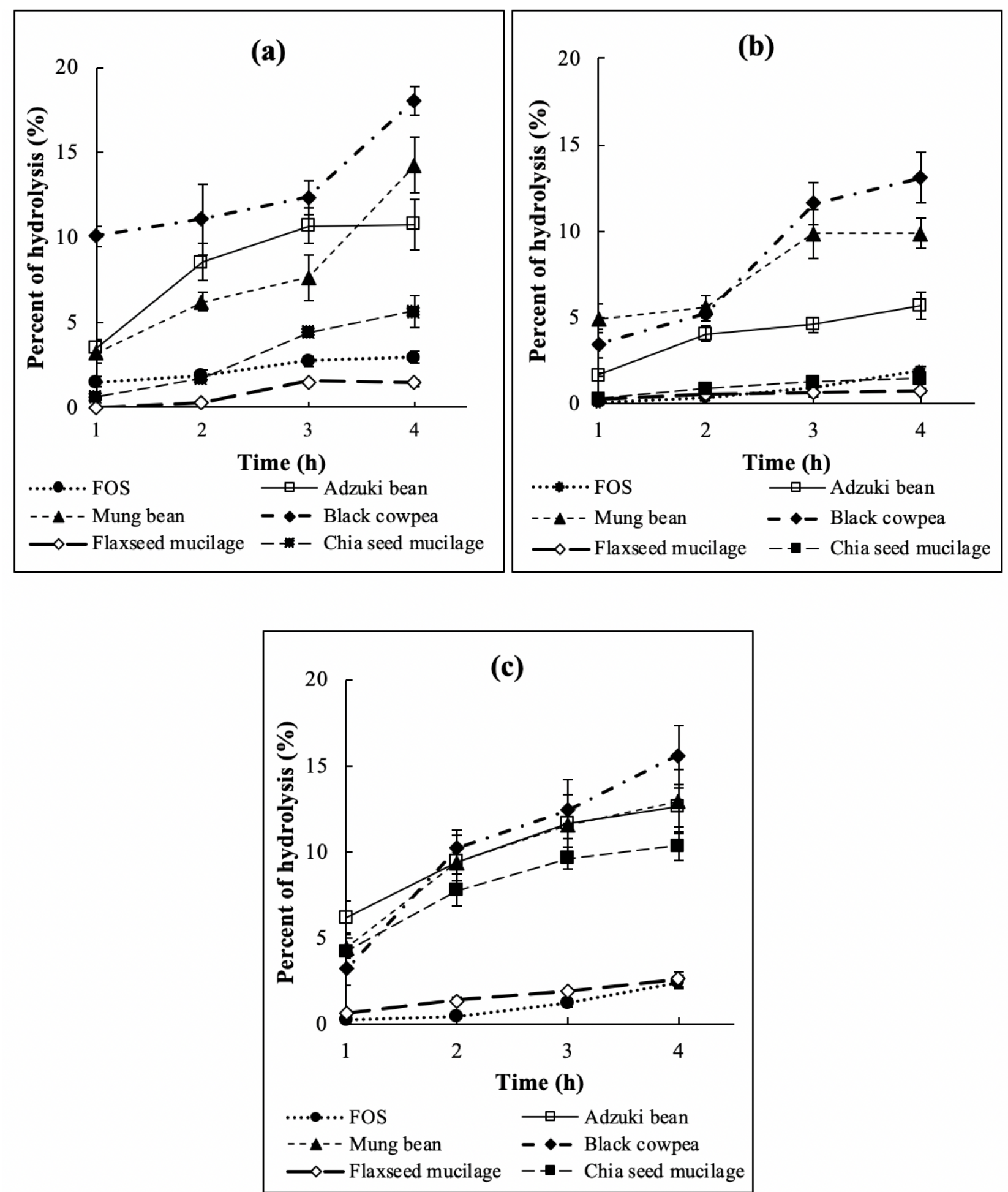

Figure 1. Percent of hydrolysis (\%) of selected legume powder and seed mucilage at artificial acid solution at (a) $\mathrm{pH} \mathrm{1,} \mathrm{(b)} \mathrm{pH} \mathrm{5,} \mathrm{and} \mathrm{(c)} \mathrm{artificial} \mathrm{pancreatin} \mathrm{enzyme} \mathrm{solution} \mathrm{at} \mathrm{pH}$ 7.0. Error bars indicate the 
standard deviation of triplicate experiments $(\mathrm{n}=3)$. FOS, fructooligosaccharides. FOS serves as positive control.

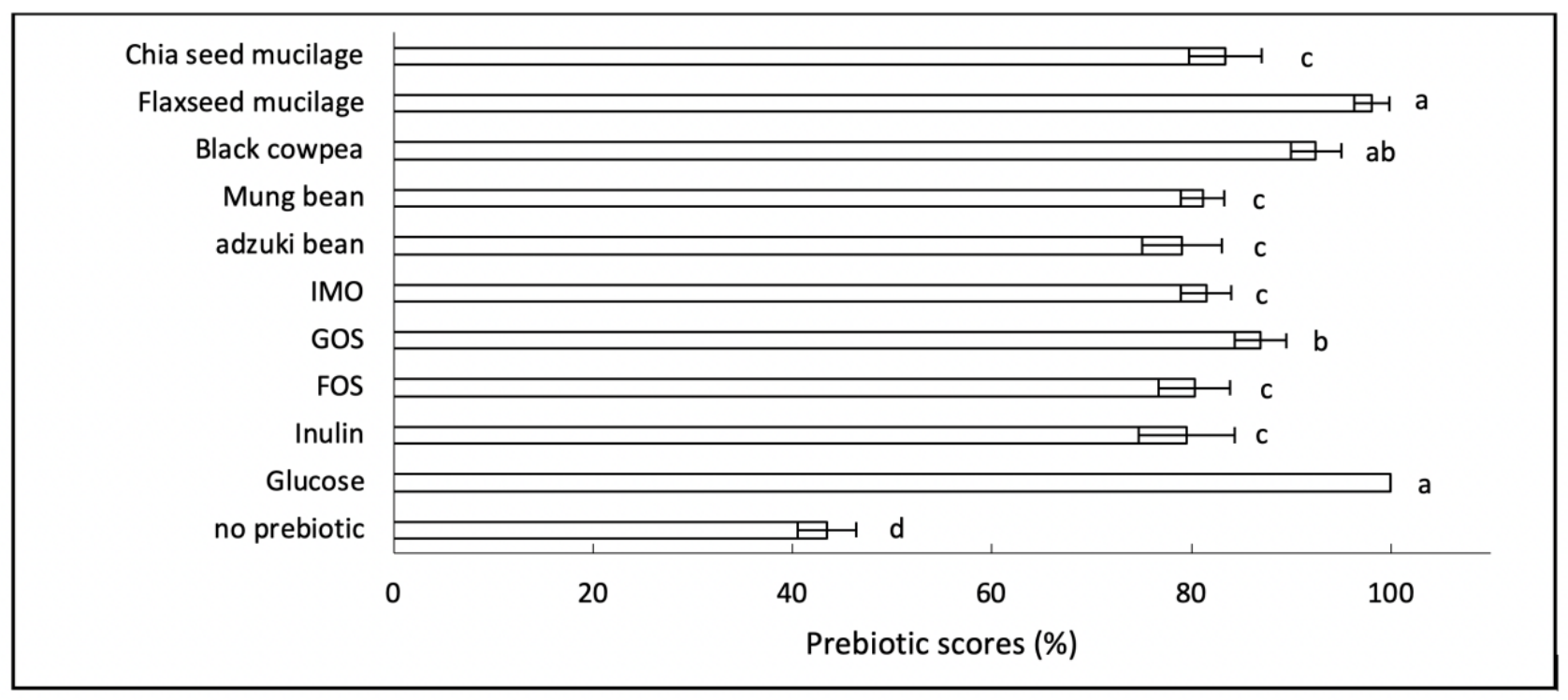

Figure 2. Prebiotic scores (\%) for Lactobacillus rbamnosus GG with different type of prebiotics. ${ }^{\text {abcd }}$ means significantly different at $\mathrm{p} \leq 0.05$ via ANOVA and Tukey's test as post hoc test. Error bars indicate the standard deviation of triplicate experiments ( $\mathrm{n}=3$ ). IMO, isomaltooligosaccharides; GOS, galactooligosaccharides; FOS, fructooligosaccharides. Glucose serves as reference; while inulin, FOS, IMO, and GOS serve as positive control. No prebiotic refers to de Man, Rogosa \& Sharpe (MRS) broth devoid glucose which serves as negative control.

On the other hand, the prebiotic score of black cowpea powder was 94\% (Figure 2), which was approximately $15 \%$ greater in prebiotic capacity than the adzuki bean and mung bean. This is probably due to higher total oligosaccharides content in black cowpea $(100.3 \mathrm{~g} / \mathrm{kg})$ as compared to adzuki bean $(62.5 \mathrm{~g} / \mathrm{kg})$ and mung bean $(65.1 \mathrm{~g} / \mathrm{kg}$ ) (Fan et al., 2015). Besides that, $L$. rhamnosus GG has been reported to ferment in different leguminous porridges (white bean, speckled bean and green lentil) after $10 \mathrm{~h}$ at $37^{\circ} \mathrm{C}$ and storage at $5^{\circ} \mathrm{C}$ for 21 days (Petruláková \& Valik, 2015). Since black cowpea and flaxseed mucilage illustrated the highest prebiotic score (Figure 2), they were included to determine the optimal concentration of the growth promotion of $L$. rbamnosus $G G$ based on its fermentation for $36 \mathrm{~h}$ at $37^{\circ} \mathrm{C}$.

Figure $3 \mathrm{a}$ and $3 \mathrm{~b}$ show the growth curves of L. rhamnosus GG supplemented with different concentrations $(0-1.0 \% \quad \mathrm{w} / \mathrm{v})$ of flaxseed mucilage and black cowpea, respectively during 36 h of fermentation at $37^{\circ} \mathrm{C}$ with MRS broth at $0 \%$ $(\mathrm{w} / \mathrm{v})$ of each sample as the negative control. Immediately after inoculation of $L$. rbamnosus GG into the respective media, L. rhamnosus GG cells experienced a lag phase for approximately $3 \mathrm{~h}$ (4.63-4.92 $\log \mathrm{CFU} / \mathrm{mL}$ ) and the cells started to grow in exponential phase, reaching maximum viability $(11.25 \log \mathrm{CFU} / \mathrm{mL})$ at $9 \mathrm{~h}$ for $0.8 \%$ $(\mathrm{w} / \mathrm{v})$ flaxseed mucilage (Figure $3 \mathrm{a})$ and $(10.50$ $10.82 \log \mathrm{CFU} / \mathrm{mL})$ at $12 \mathrm{~h}$ for $0.4-1.0 \%(\mathrm{w} / \mathrm{v})$ black cowpea (Figure 3b).

The L. rbamnosus GG cells in glucose-free MRS broth $(0.0 \% \mathrm{w} / \mathrm{v}$ flaxseed mucilage or black cowpea) reached stationary phase after $15 \mathrm{~h}$ of incubation $\left(\sim 10^{9} \mathrm{CFU} / \mathrm{mL}\right)$. As the concentration of flaxseed mucilage (from $0.0 \%$ to $0.8 \%(\mathrm{w} / \mathrm{v}$ ) and black cowpea (from $0.0 \%$ to $0.4 \%(\mathrm{w} / \mathrm{v})$ ) increase, more nutrients are available for cell division, therefore accelerated growth curve was observed by at least $33 \%$ as compared to the negative control. These outcomes were compatible with the study from Majeed et al. (2018a), where the concentrations of galactomannan from fenugreek seed fibre were proportional to the growth stimulation effect of Bacillus coagulans MTCC 5856 after $24 \mathrm{~h}$ of fermentation. The rapid growth of $L$. rhamnosus GG in the media supplemented with flaxseed 
mucilage and black cowpea during the log and stationary phases could results in the decline in the cell population (27-36 h of incubation) due to the exhaustion in nutrients and accumulation of toxic waste compounds from the cell metabolic activities (Ho et al., 2017).

Flaxseed mucilage at $0.8 \%(\mathrm{w} / \mathrm{v})$ and black cowpea at $0.4 \%(\mathrm{w} / \mathrm{v})$ provide the optimal growth stimulatory effect in L. rhamnosus GG. The slow growth of the Lactobacillus strain at $1.0 \%(\mathrm{w} / \mathrm{v})$ flaxseed mucilage concentration may probably attribute to the increase in the viscosity (Bustamante et al., 2015). Besides that, a similar result was also reported by Savedboworn et al.
(2017) where $2 \%$ inulin showed higher probiotic growth than 3\% inulin. The study explained that the probiotic with higher prebiotic concentration may produce a higher amount of acid and resulted in lower probiotic growth. The growth curve of high black cowpea concentrations (0.6-1.0\%) were not significantly different $(p>0.05)$ from the $0.4 \%(\mathrm{w} / \mathrm{v})$. These findings were supported by Wang et al. (2006) who underlined that no difference in bacteria densities of lactobacilli and bifidobacterial were detected in the media supplied with $1.0 \%-3.0 \%(\mathrm{w} / \mathrm{v})$ of alginate oligosaccharides
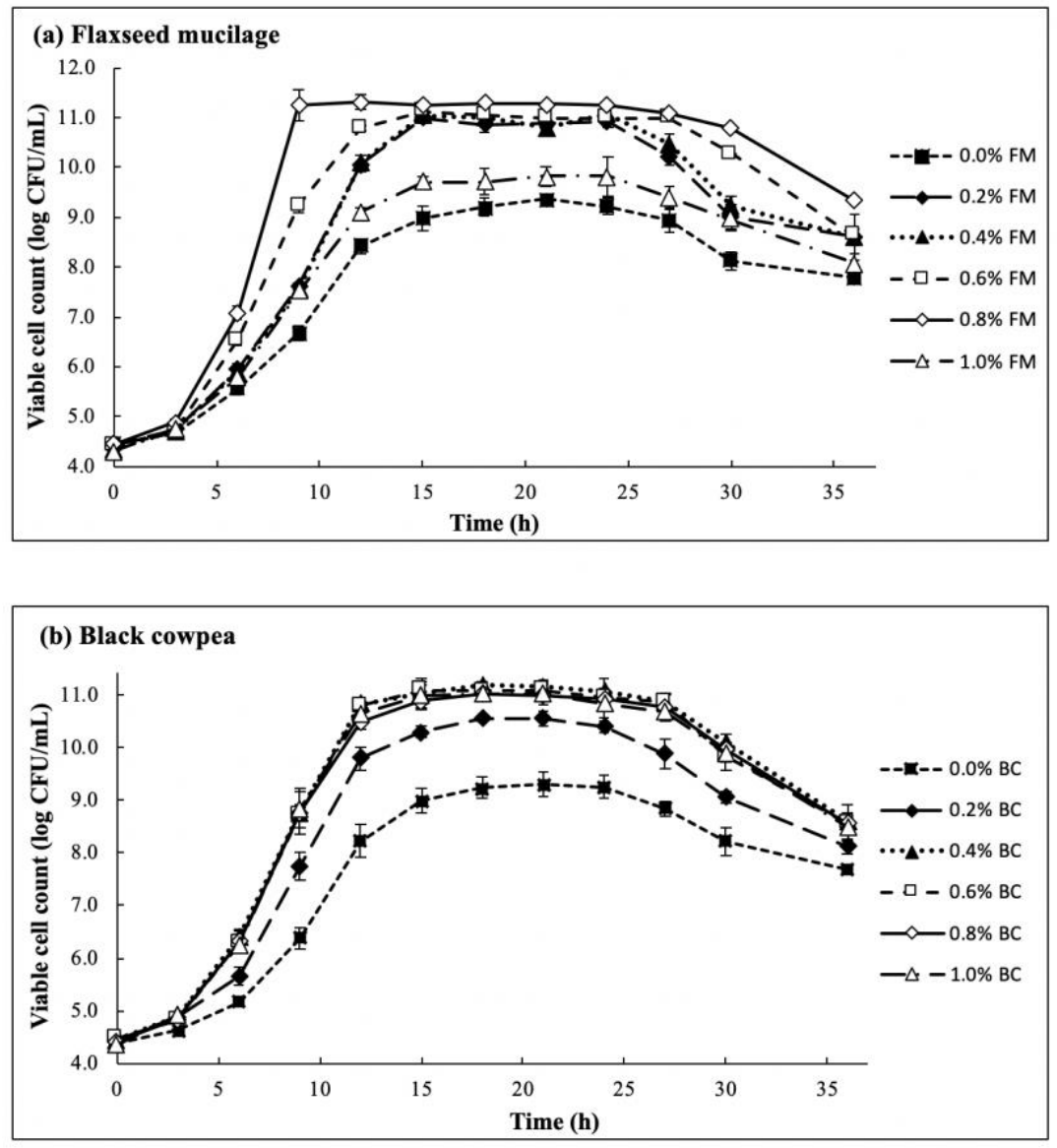

Figure 3. Growth curve of Lactobacillus rhamnosus GG based on viable cell count over time $(0-36 \mathrm{~h})$ under different concentrations $(0-1.0 \% \mathrm{w} / \mathrm{v})$ of (a) flaxseed mucilage and (b) black cowpea powder. Error bars indicate the standard deviation of triplicate experiments $(n=3) . \quad F M$, flaxseed mucilage; BC, black cowpea.

The fermentation of both flaxseed mucilage and black cowpea was evident by the reduction in $\mathrm{pH}$ of the media (Figure 4) and an increase in the titratable acidity (TA) (Figure 5). Figure 4 shows the initial $\mathrm{pH}$ of all the growth media were at 5.55.6. The $\mathrm{pH}$ of the growth media dropped to $3.5-$ 3.6 for flaxseed mucilage (Figure 4a) and 3.5-3.7 for black cowpea (Figure $4 \mathrm{~b}$ ) at the $27^{\text {th }} \mathrm{h}$ of incubation as the cells entered the death phase.
This demonstrates that the low $\mathrm{pH}$ of the growth media resulted in the decline in L. rbamnosus GG's viability as the optimum $\mathrm{pH}$ of $L$. rbamnosus GG ranged from 4.5 to 6.4 (Valík et al., 2008).

After $9 \mathrm{~h}$ of incubation, $\mathrm{pH}$ of the growth media containing $0.8 \%(\mathrm{w} / \mathrm{v})$ flaxseed mucilage was the lowest which emphasized the high production of the lactic acid (Figure 4a). In contrast, the decrease in $\mathrm{pH}$ of the media with 
$0.0 \% \quad(\mathrm{w} / \mathrm{v})$ flaxseed mucilage was less pronounced due to the slower cell division in the $\log$ phase. Furthermore, the reduction in $\mathrm{pH}$ was not significantly different $(\mathrm{p}>0.05)$ for black cowpea concentrations above $0.4 \% \quad(\mathrm{w} / \mathrm{v})$, implying that the synthesis of the short-chain fatty acids was comparable as shown in Figure 5b. The obtained results were compatible with the $\mathrm{pH}$ obtained from the $24 \mathrm{~h}$ fermentation of flaxseed mucilage by $L$. acidophilus $\mathrm{La}-5$ at different concentrations (Bustamante et al., 2015).

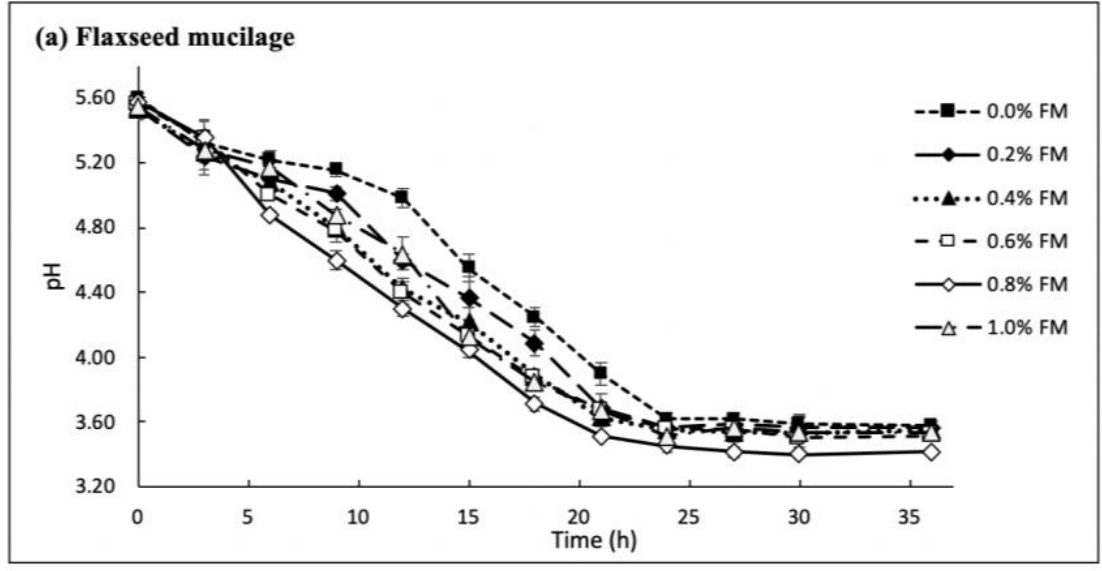

(b) Black cowpea

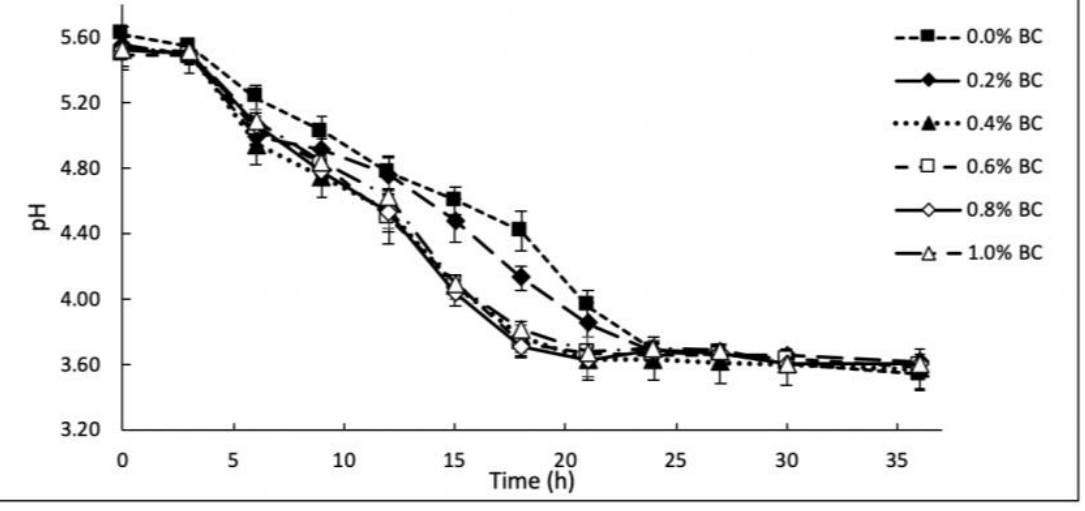

Figure 4.The $\mathrm{pH}$ of growth medium containing Lactobacillus rhamnosus GG and $0-1.0 \%$ (w/v) of (a) flaxseed mucilage and (b) black cowpea powder at $36 \mathrm{~h}$ of fermentation. Error bars indicate the standard deviation of triplicate experiments $(n=3)$. FM, flaxseed mucilage; BC, black cowpea.
Lactic acid was synthesized as a major by-product from the metabolism of carbon source by $L$. rbamnosus GG (de Keersmaecker et al., 2006). Both TA curves showed similar pattern such that the percent of TA is directly proportional to the incubation time, especially during the exponential phase. Figure 5 shows that the percent of TA was elevated as the concentration of flaxseed mucilage and black cowpea increases. This is probably due to rapid utilization of the nutrients for growth and more lactic acid was produced, with an exception for $1.0 \%(\mathrm{w} / \mathrm{v})$ flaxseed mucilage (Figure 5a) while the concentration of black cowpea above $0.4 \%(w / v)$ has no significant effect $(p>0.05)$ on the increase in percent TA (Figure $5 b$ ).
At the end of the fermentation $(36 \mathrm{~h})$, the final TA for $0.8 \%$ flaxseed mucilage was $2.32 \%$ (Figure $5 \mathrm{a}$ ) and $2.03-2.07 \%$ for $0.4-1.0 \%$ black cowpea (Figure 5b), respectively. The results were also consistent with Ho et al. (2017) highlighted that higher population of the $L$. acidophilus and $B$. bifidum at $24 \mathrm{~h}$ of incubation as a result of higher enzymatic activity to hydrolyse the oligosaccharides of citrus pectin enzyme hydrolysate into monosaccharides and greater ability to utilize monosaccharides. Thus, a higher amount of lactic acid was produced. Flaxseed mucilage at $0.8 \%(\mathrm{w} / \mathrm{v})$ and black cowpea at $0.4 \%$ $(\mathrm{w} / \mathrm{v})$ was the optimum concentration in providing most favourable growth stimulatory effect in L. rbamnosus GG. 

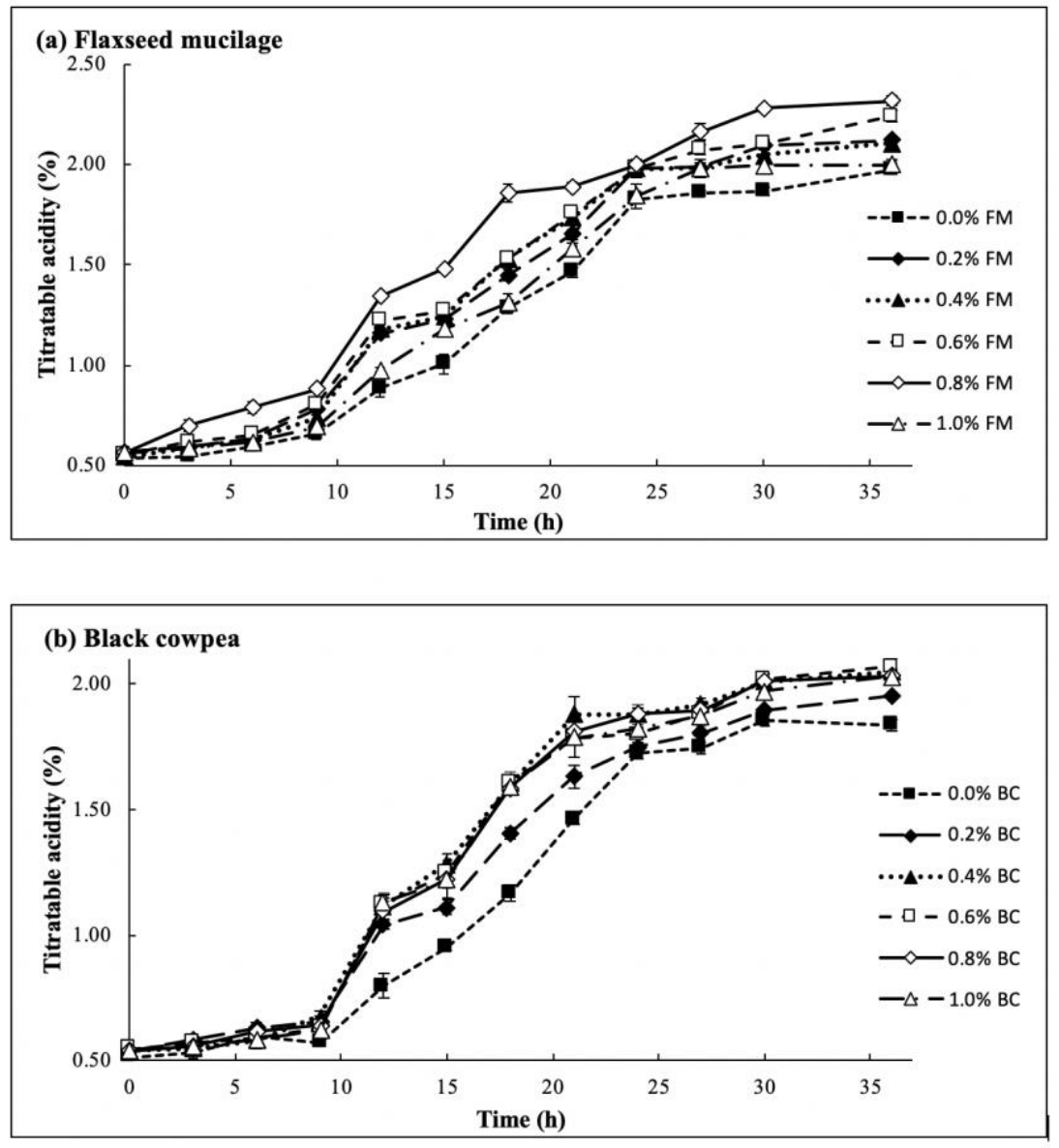

Figure 5. Titratable acidity (TA) of growth medium containing Lactobacillus rhamnosus GG and $0-1.0 \%$ (w/v) of (a) flaxseed mucilage and (b) black cowpea powder at $36 \mathrm{~h}$ of fermentation. Error bars indicate the standard deviation of triplicate experiments $(n=3) . \quad F M$, Flaxseed mucilage; BC, black cowpea.

\section{CONCLUSION}

This study provides the comparison of different selected legumes and seed mucilage on the resistance towards digestibility and the prebiotic capacity on the L. rbamnosus GG. The flaxseed mucilage exhibited similar resistance towards artificial acid and pancreatic hydrolysis as compared to FOS. However, flaxseed mucilage and black cowpea presented the highest prebiotic score that was not significantly different from the glucose reference. The optimum concentration of flaxseed mucilage and black cowpea were $0.8 \%$ and $0.4 \%(\mathrm{w} / \mathrm{w})$, respectively due to the highest in L. rhamnosus GG growth promotion. The current study provides an alternative prebiotic source that is suitable for the production of symbiotic functional food products along with the commercial probiotic strains of L. rhamnosus GG.

\section{ACKNOWLEDGEMENTS}

This work was supported by Pioneer Scientist Incentive Fund (PSIF) grant (Proj-In-FAS-055) and UCSI Research Excellence and Innovation Grant (REIG) (REIG-FAS-2020-003) from UCSI University.

\section{REFERENCES}

Adamu, A. S., Ajayi, M. G., \& Oyetunde, J. G. 2016. Inorganic and proximate nutritional composition of common beans in Nigeria. European Journal of Pure and Applied Chemistry 3(2): 25-28.

Amezcua-Allieri, M. A., Sánchez Durán, T., \& Aburto, J. 2017. Study of chemical and enzymatic hydrolysis of cellulosic material to obtain fermentable sugars. Journal of Chemistry 2017: 1-9.

AOAC. 1998. Official methods of analysis. Maryland: AOAC International.

Azmi, A. F. M. N., Mustafa, S., Hashim, D. M., \& Manap, Y. A. 2012. Prebiotic activity of polysaccharides extracted from 
Gigantochloa levis (buluh beting) shoots. Molecules 17(2): 1635-1651.

Bernacchia, R., Preti, R., \& Vinci, G. 2014. Chemical composition and health benefits of flaxseed. Austin Journal of Nutrition and Food Sciences 2(8): 1-9.

Brishti, F. H., Zarei, M., Muhammad, S. K. S., Ismail-Fitry, M. R., Shukri, R., \& Saari, N. 2017. Evaluation of the functional properties of mung bean protein isolate for development of textured vegetable protein. International Food Research Journal 24(4): 1595-1605.

Bustamante, M., Oomah, B. D., Rubilar, M., \& Shene, C. 2017. Effective Lactobacillus plantarum and Bifidobacterium infantis encapsulation with chia seed (Salvia hispanica L.) and flaxseed (Linum usitatissimum L.) mucilage and soluble protein by spray drying. Food Chemistry 216: 97-105.

Bustamante, M., Villarroel, M., Rubilar, M., \& Shene, C. 2015. Lactobacillus acidophilus La-05 encapsulated by spray drying: Effect of mucilage and protein from flaxseed (Linum usitatissimum L.). LWT - Food Science and Technology 62(2): 1162-1168.

Carding, S., Verbeke, K., Vipond, D. T., Corfe, B. M., \& Owen, L. J. 2015. Dysbiosis of the gut microbiota in disease. Microbial Ecology in Health \& Disease 26: 26191.

Chan, L. Y., \& Pui, L. P. 2020. Microencapsualtion of Lactobacillus acidophilus 5 with isomalto-oligosaccharides. Carpatbian Journal of Food Science and Technology 12(2): 26-36.

Chavan, R., Saxena, K., \& Tigote, D. 2015. Optimization of acid hydrolysis process for free glucose recovery from starch. International Journal of Innovative Science, Engineering \& Tecbnology 2(12): 55-58.

Chew, S. C., Tan, C. H., Pui, L. P., Chong, P. N., Gunasekaran, B., \& Lin, N. K. 2019. Encapsulation technologies: A tool for functional foods development. International Journal of Innovative Technology and Exploring Engineering 8(5s): 154-160.

Cruz-Rubio, J. M., Loeppert, R., Viernstein, H., \& Praznik, W. 2018. Trends in the use of plant non-starch polysaccharides within food, dietary supplements, and pharmaceuticals: Beneficial effects on regulation and wellbeing of the intestinal tract. Scientia Pharmaceutica 86(49): 1-13.

De Keersmaecker, S. C. J., Verhoeven, T. L. A., Desair, J., Marchal, K., Vanderleyden, J., \& Nagy, I. 2006. Strong antimicrobial activity of Lactobacillus rbamnosus GG against Salmonella typhimurium is due to accumulation of lactic acid. FEMS Microbiology Letters 259(1): 89-96.

Dubois, M., Gilles, K. A., Hamilton, J. K., Rebers, P. A., \& Smith, F. 1956. Colorimetric method for determination of sugars and related substances. Analytical Chemistry 28(3): 350-356.

Emaga, T.H., Rabetafika, H.-N., Blecker, C., \& Paquot, M. 2012. Kinetics of the hydrolysis of polysaccharide galacturonic acid and neutral sugars chains from flaxseed mucilage. Biotechnologie, Agronomie, Société et Environnement 16(2): 139_ 147.

Esmaeilzadeh, J., Nazemiyeh, H., Maghsoodi, M., \& Lotfipour, F. 2016. Evaluation of the effect of psyllium on the viability of Lactobacillus acidophilus in alginate-polyl lysine beads. Advanced Pharmaceutical Bulletin 6(3): 337-343.

Esparza, Y., Leyton, A., Rubilar, M., \& Shene, C. 2011. Cinetica de extraccion y actividad prebiotica del mucilago de linaza. VIII Congreso Iberoamericano de Ingeniería. pp. 24-26. Lima, Peru.

Fan, P. H., Zang, M. T., \& Xing, J. 2015. Oligosaccharides composition in eight food legumes species as detected by high-resolution mass spectrometry. Journal of the Science of Food and Agriculture 95(11): 2228-2236.

Faridah, D. N., Riana, R. Z. H., Kusumaningrum, H. D., \& Faridah, D. N. 2017. Potential prebiotic properties by in vitro in arrowroot starch (Marantha arundinaceae L.) a combination of acidic, enzymatic, and physical modification. Der Pharma Chemica 9(1): 15-21.

Figueroa-González, I., Rodríguez-Serrano, G., Gómez-Ruiz, L., García-Garibay, M., \& Cruz-Guerrero, A. 2019. Prebiotic effect of commercial saccharides on probiotic bacteria isolated from commercial products. Food Science and Technology 39(3): 747-753.

Gagnière, J., Raisch, J., Veziant, J., Barnich, N., Bonnet, R., Buc, E., Bringer, M. A., Pezet, D., \& Bonnet, M. 2016. Gut microbiota imbalance and colorectal cancer. World Journal of Gastroenterology 22(2): 501-518.

Gibson, G. R., Hutkins, R., Sanders, M. E., Prescott, S. L., Reimer, R. A., Salminen, S. J., Scott, K., Stanton, C., Swanson, K. S., Cani, P. D., Verbeke, K., \& Reid, G. 2017. The International Scientific Association for Probiotics and Prebiotics (ISAPP) consensus statement on the definition and scope of prebiotics. Nature Reviews Gastroenterology and Hepatology 14(8): 491-502.

Hamid, S., Muzaffar, S., Wani, I. A., Masoodi, F. A., \& Bhat, M. M. 2016. Physical and cooking characteristics of two cowpea cultivars grown in temperate Indian climate. Journal of the Saudi Society of Agricultural Sciences 15(2): 127-134.

Heeney, D. D., Gareau, M. G., \& Marco, M. L. 2018. Intestinal Lactobacillus in health and disease, a driver or just along for the ride? Current Opinion in Biotechnology 49: 140-147.

Hill, C., Guarner, F., Reid, G., Gibson, G. R., Merenstein, D. J., Pot, B., Morelli, L., Canani, R. B., Flint, H. J., Salminen, S., Calder, P. C., \& Sanders, M. E. 2014. The International Scientific Association for Probiotics and Prebiotics consensus statement on the scope and appropriate use of the term probiotic. Nature Reviews Gastroenterology and Hepatology 11(8): 506-514.

Ho, Y. Y., Lin, C. M., \& Wu, M. C. 2017. Evaluation of the prebiotic effects of citrus pectin hydrolysate. Journal of Food and Drug Analysis 25(3): 550-558.

Kankainen, M., Paulin, L., Tynkkynen, S., Von Ossowski, I., Reunanen, J., Partanen, P., Satokari, R., Vesterlund, S., Hendrickx, A. P. A., Lebeer, S., de Keersmaecker, S. C. J., Vanderleyden, J., Hämäläinen, T., Laukkanen, S., Salovuori, N., Ritari, J., Alatalo, E., Korpela, R., Mattila-Sandholm, T., Lassig, A., Hatakka, K., Kinnunen, K. T., Karjalainen, H., Saxelin, M., Laakso, K., Surakka, A., Palva, A., Salusjärvi, T., Auvinen, P., \& de Vos, W. M. 2009. Comparative genomic analysis of Lactobacillus rhamnosus GG reveals pili containing a human-mucus binding protein. Proceedings of the National Academy of Sciences of the United States of America 106(40): 17193-17198.

Khorasani, A. C., \& Shojaosadati, S. A. 2016. Bacterial nanocellulose-pectin bionanocomposites as prebiotics against drying and gastrointestinal condition. International Journal of Biological Macromolecules 83: 9-18.

Kreitschitz, A., \& Gorb, S. N. 2018. The micro- and nanoscale spatial architecture of the seed mucilage-Comparative study of selected plant species. PLOS ONE 13(7): 1-15.

Lai, J. T., Lai, K. W., Zhu, L. Y., Nyam, K. L., \& Pui, L. P. 2020 a. Microencapsulation of Lactobacillus plantarum 299v and its storage in kuini juice. Malaysian Journal of Microbiology 16(4): 235-244.

Lai, K., How, Y., \& Pui, L. 2020b. Microencapsulation of Lactobacillus rhamnosus GG with flaxseed mucilage using coextrusion technique. Journal of Microencapsulation 0(0): 1-14.

Lai, K. W., How, Y. H., \& Pui, L. P. 2020c. Storage stability of microencapsulated Lactobacillus rhamnosus GG in hawthorn berry tea with flaxseed mucilage. Journal of Food Processing and Preservation 00: e14965.

Lin, B., Gong, J., Wang, Q., Cui, S., Yu, H., \& Huang, B. 2011. Invitro assessment of the effects of dietary fibers on microbial fermentation and communities from large intestinal digesta of pigs. Food Hydrocolloids 25(2): 180-188. 
Majeed, M., Majeed, S., Nagabhushanam, K., Arumugam, S., Natarajan, S., Beede, K., \& Ali, F. 2018a. Galactomannan from Trigonella foenum-graecum L. seed: Prebiotic application and its fermentation by the probiotic Bacillus coagulans strain MTCC 5856. Food Science and Nutrition 6(3): 666-673.

Majeed, M., Nagabhushanam, K., Arumugam, S., Natarajan, S., Majeed, S., Pande, A., Beede, K., \& Ali, F. 2018b. Cranberry seed fibre: A promising prebiotic fibre and its fermentation by the probiotic Bacillus coagulans MTCC 5856. International Journal of Food Science and Technology 53(7): 1640-1647.

Miller G. L. 1959. Use of dinitrosaIicylic acid reagent for determination of reducing sugar. Analytical Chemistry 31(3): 426-428.

Miloski, K., Wallace, K., Fenger, A., Schneider, E., \& Bendinskas, K. 2008. Comparison of biochemical and chemical digestion and detection methods for carbohydrates. American Journal of Underyraduate Research 7(2): 7-18.

Monk, J. M., Lepp, D., Wu, W., Pauls, K. P., Robinson, L. E., \& Power, K. A. 2017. Navy and black bean supplementation primes the colonic mucosal microenvironment to improve gut health. Journal of Nutritional Biochemistry 49: 89-100.

Mueller, M., Čavarkapa, A., Unger, F. M., Viernstein, H., \& Praznik, W. 2017. Prebiotic potential of neutral oligo- and polysaccharides from seed mucilage of Hyptis suaveolens. Food Chemistry 221: 508-514.

Muñoz, L. A., Cobos, A., Diaz, O., \& Aguilera, J. M. 2012. Chia seeds: Microstructure, mucilage extraction and hydration. Journal of Food Engineering 108(1): 216-224.

Naran, R., Chen, G., \& Carpita, N. C. 2008. Novel rhamnogalacturonan I and arabinoxylan polysaccharides of flax seed mucilage. Plant Physiology 148(1): 132-141.

Ng, S. L., Lai, K. W., Nyam, K. L., \& Pui, L. P. 2019. Microencapsulation of Lactobacillus plantarum 299v incorporated with oligofructose in chitosan coated-alginate beads and its storage stability in ambarella juice. Malaysian Journal of Microbiology 15(5): 408-418.

Nowak, D., Gosiliński, M., \& Wojtowicz, E. 2016. Comparative analysis of the antioxidant capacity of selected fruit juices and nectars: Chokeberry juice as a rich source of polyphenols. International Journal of Food Properties 19(6): 1317-1324.

Pastell, H., Westermann, P., Meyer, A. S., Päivi, T., \& Tenkanen, M. 2009. In vitro fermentation of arabinoxylan-derived carbohydrates by bifidobacteria and mixed fecal microbiota. Journal of Agricultural and Food Chemistry 57(18): 8598-8606.

Petrova, M. I., Macklaim, J. M., Wuyts, S., Verhoeven, T., Vanderleyden, J., Gloor, G. B., Lebeer, S., \& Reid, G. 2018. Comparative genomic and phenotypic analysis of the vaginal probiotic Lactobacillus rhamnosus GR-1. Frontiers in Microbiology 9(1278): 1-12.

Petruláková, M., \& Valík, L. 2015. Legumes as potential plants for probiotic strain Lactobacillus rhamnosus GG. Acta Universitatis Agriculturae et Silviculturae Mendelianae Brunensis 63(5): 1505 1511.

Piergiovanni, A. R., \& Gatta, C. D. 1994. $\alpha$-Amylase inhibitors in cowpea (Vigna unguiculata): Effects of soaking and cooking methods. Food Chemistry 51(1): 79-81.

Ramakrishna, B. S. 2013. Role of the gut microbiota in human nutrition and metabolism. Journal of Gastroenterology and Hepatology (Australia) 28(S4): 9-17.

Saad, A. M., Osman, A. O. M., Mohamed, A. S., \& Ramadan, M. F. 2020. Enzymatic hydrolysis of Phaseolus vulgaris protein isolate: Characterization of hydrolysates and effect on the quality of minced beef during cold storage. International Journal of Peptide Research and Therapeutics 26(1): 567-577.

Sánchez, B., Saad, N., Schmitter, J. M., Bressollier, P., \& Urdaci, M. C. 2010. Adhesive properties, extracellular protein production, and metabolism in the Lactobacillus rbamnosus
GG strain when grown in the presence of mucin. Journal of Microbiology and Biotechnology 20(6): 978-984.

Savedboworn, W., Niyomrat, S., Naknovn, J., \& Phattayakorn, K. 2017. Impact of inulin on viability and storage stability of probiotic Lactobacillus plantarum TISTR 2075 in fermented rice extract. Agriculture and Natural Resources 51(6): 463-469.

Siang, S. C., Wai, L. K., Lin, N. K., \& Phing, P. L. 2019. Effect of added prebiotic (isomalto-oligosaccharide) and coating of beads on the survival of microencapsulated Lactobacillus rhamnosus GG. Food Science and Technology 39: 601-609.

Singer, F., Taha, F., Mohamed, S., Gibriel, A., \& El-Nawawy, M. 2011. Preparation of mucilage/protein products from flaxseed. American Journal of Food Technology 6(4): 260-278.

Singla, V., \& Chakkaravarthi, S. 2017. Applications of prebiotics in food industry: A review. Food Science and Technology International 23(8): 649-667.

Slavin, J. 2013. Fiber and prebiotics: Mechanisms and health benefits. Nutrients 5(4): 1417-1435.

Soltani, M., Hekmat, S., \& Ahmadi, L. 2018. Microbial and sensory evaluation of probiotic yoghurt supplemented with cereal/pseudo-cereal grains and legumes. International Journal of Dairy Technology 71: 141-148.

Succi, M., Tremonte, P., Pannella, G., Tipaldi, L., Cozzolino, A., Romaniello, R., Sorrentino, E., \& Coppola, R. 2017. Precultivation with selected prebiotics enhances the survival and the stress response of Lactobacillus rbamnosus strains in simulated gastrointestinal transit. Frontiers in Microbiology 8: $1-11$.

Suri, S., Passi, S., \& Goyat, J. 2016. Chia seed (Salvia Hispanica L.) - A new age functional food. International Journal of Advanced Technology in Engineering and Science 4(3): 286-299.

Taiseer, M. A. B., Youssef, M. M., \& Moharram, H. A. 2014. Analysis, health benefits and applications of prebiotics: A review. Alexandria Journal of Food Science and Technology 11(2): 25-37.

Thakur, K., Xu, G. Y., Zhang, J. G., Zhang, F., Hu, F., \& Wei, Z. J. 2018. In vitro prebiotic effects of bamboo shoots and potato peel extracts on the proliferation of lactic acid bacteria under simulated GIT conditions. Frontiers in Microbiology 9(2114): 1-14.

Thuaytong, W., \& Anprung, P. 2011. Bioactive compounds and prebiotic activity in thailand-grown red and white guava fruit (Psidium guajava L.). Food Science and Technology International 17(3): 205-212.

Tungland, B. 2018. Dysbiosis of the microbiota: Therapeutic strategies utilizing dietary modification, pro- and prebiotics and fecal transplant therapies in promoting normal balance and local GI functions. In: Human microbiota in health and disease. Ed. Tungland, B. pp. 381-419. London: Academic Press.

Ueda, Y., Itoh, T., Nukaya, I., Kawashima, I., Okugawa, K., Yano, Y., Yamamoto, Y., Naitoh, K., Shimizu, K., Imura, K., Fuji, N., Fujiwara, H., Ochiai, T., Itoi, H., Sonoyama, T., Hagiwara, A., Takesako, K., \& Yamagishi, H. 2004. Dendritic cell-based immunotherapy of cancer with carcinoembryonic antigen-derived, HLA-A24-restricted CTL epitope: Clinical outcomes of 18 patients with metastatic gastrointestinal or lung adenocarcinomas. International Journal of Oncology 24(4): 909-917.

Valík, L., Medved’ová, A., \& Liptáková, D. 2008. Characterization of the growth of Lactobacillus rbamnosus GG in milk at suboptimal temperatures. Journal of Food and Nutrition Research 47(2): 60-67.

Wang, Y. C., Yu, R. C., \& Chou, C. C. 2006. Antioxidative activities of soymilk fermented with lactic acid bacteria and bifidobacteria. Food Microbiology 23(2): 128-135.

Wani, I. A., Sogi, D. S., Wani, A. A., Gill, B. S., \& Shivhare, U. S. 2010. Physico-chemical properties of starches from Indian 
kidney bean (Phaseolus vulgaris) cultivars. International Journal of Food Science and Technology 45(10): 2176-2185.

Watson, D., O'Connell Motherway, M., Schoterman, M. H. C., van Neerven, R. J. J., Nauta, A., \& Van Sinderen, D. 2013. Selective carbohydrate utilization by lactobacilli and bifidobacteria. Journal of Applied Microbiology 114(4): 11321146.

Winham, D. M., Hutchins, A. M., \& Thompson, S. V. 2017. Glycemic response to black beans and chickpeas as part of a rice meal: A randomized cross-over trial. Nutrients $9(10)$ : $1-12$.

Wisessing, A., Engkagul, A., Wongpiyasatid, A., \& Choowongkomon, K. 2010. Biochemical characterization of the $\alpha$-Amylase inhibitor in mungbeans and its application in inhibiting the growth of callosobruchus maculatus. Journal of Agricultural and Food Chemistry 58(4): 2131-2137.

Wongputtisin, P., \& Khanongnuch, C. 2015. Prebiotic properties of crude oligosaccharide prepared from enzymatic hydrolysis of basil seed gum. Food Science and Biotechnology 24(5): 1767-1773.

Wu, H., Rui, X., Li, W., Chen, X., Jiang, M., \& Dong, M. 2015. Mung bean (Vigna radiata) as probiotic food through fermentation with Lactobacillus plantarum B1-6. LWT - Food Science and Tecbnology 63(1): 445-451.

Yee, W. L., Yee, C. L., Lin, N. K., \& Phing, P. L. 2019. Microencapsulation of Lactobacillus acidophilus NCFM incorporated with mannitol and its storage stability in mulberry tea. Ciência e Agrotecnologia 43: e005819.

Yeung, T. W., Üçok, E. F., Tiani, K. A., McClements, D. J., \& Sela, D. A. 2016. Microencapsulation in alginate and chitosan microgels to enhance viability of Bifidobacterium longum for oral delivery. Frontiers in Microbiology 7(494): 1-11.

Yong, A. K. L., Lai, K. W., Ghazali, H. M., Chang, L. S., \& Pui, L. P. 2020. Microencapsulation of Bifidobacterium animalis subsp. lactis BB-12 with mannitol. Asia-Pacific Journal of Molecular Biology and Biotechnology 28(2): 32-42.

Zaman, S. A., \& Sarbini, S. R. 2016. The potential of resistant starch as a prebiotic. Critical Reviews in Biotechnology 36(3): $578-584$.

Zhang, L., Wang, X. F., Liu, H., Yu, L., Wang, Y., Simon, G. P., \& Qian, J. 2018. Effect of plasticizers on microstructure, compatibility and mechanical property of hydroxypropyl methylcellulose/hydroxypropyl starch blends. International Journal of Biological Macromolecules 119(1): 141-148. 